Interdisciplinary Studies of Complex Systems

No. 18 (2021) 87-96

(C) N. Kondratieva

https://doi.org/10.31392/iscs.2021.18.087

\title{
Time NOTES
}

\author{
Natalia Kondratieva ${ }^{1}$
}

\section{ЗАПИСКИ О ВРЕМЕНИ}

\author{
Наталия Кондратъева
}

\begin{abstract}
What is time? Time is a frequently and widely used word. That is why the concept of time seems very simple and close to everyone. Back in the fifth century blessted Augustine noticed that this clarity exists as long as we do not focus our attention on this concept. And then we get to a deadlock. However, you cannot give yourself an account of what we are measuring when we are measuring time.
\end{abstract}

«Настоящий автор хорошо сознает, что он не первый, кто обсуждает вопросы, составляющие содержания данной статьи и что догадки его предшественников были либо признаны неверными, либо недоказуемыми, следовательно, в конечном счете неинтересными. Он не будет слишком удивлен, если настоящая статья разделит судьбу этих предшественников. Он чувствует, однако, что многие из более ранних спекуляций по этому предмету, даже если их нельзя оправдать, стимулировали наше мышление и эмоции и вносили вклад в возрождение научного интереса к данному вопросу».

Юджин Вигнер [1]

«Никакой отдельной науки о времени как предмете, объекте или явлении не существует. Что такое время? Время есть часто и широко употребляемое слово и понятие и потому само по себе кажется очень простым и всем близким. Но как еще заметил в $\mathrm{V}$ веке блаженный Августин эта простота и понятность существует до тех пор, пока мы не сосредотачиваем на этом понятии своего внимания, вдумываемся и пытаемся точнее определить, что же оно такое? И тогда мы положительно становимся в тупик. И решительно нельзя дать себе отчет, что же мы измеряем, когда его измеряем».

Геннадий Аксенов [2]

\footnotetext{
${ }^{1}$ nkondr24@gmail.com
} 


\section{Запись 1}

Первобытные люди имели смутные представления о времени. Животные не имеют понятия времени, не знают ничего о начале и конце жизни. Время начинает быть с определенной стадии развития человеческого сознания и мышления. Человеческое время привязано к астрономическому ритму вращения небесных тел: вращению Земли вокруг своей оси - сутки или 24 часа, вращению Земли вокруг Солнца - год или 365 суток и т. д.

Вращение небесных тел подчинено закону цикличности, однако круги циклов не накладываются один на другой, а развиваются по спирали, что рождает прошлое и будущее и создает эволюционное движение. Мысленно мы можем обращаться к прошлому и строить будущее. Мы можем рассматривать настоящее как разрез явлений во времени. Если бы удалось по орбите движения Земли устремиться в направлении, обратном ее движению, то время бы остановилось. Если скорость движения еще повысить, то прошлое Земли можно было бы увидеть в соответствии с быстротой движения вспять по орбите. Орбита не повторяется в пространстве, ибо движение Земли спирально в ее расширяемомся устремленном беге вместе со всей солнечной системой.

Наличие количества времени у человека в котором он существует, определяется его сознанием. Человек имеет столько времени для своих планов, сколько вмещают его мысли. Если человек живет планами поехать летом в отпуск и купить новый диван, то у него есть несколько месяцев. Если человек мыслит себя в рамках своей земной жизни, - у него есть несколько десятков лет. Если он допускает и думает о существовании после физической смерти, то у него сотни или тысячи лет. И так далее...

Восприятие времени человеком так же относительно и зависит от плана на котором находится сознание: вот вы летите в самолете и ждете когда закончится время полета, ваше сознание находится на физическом плане и вы следите за движением пассажиров, стюардесс, за облаками в иллюминаторе и т. д., - время длится долго, но если во время полета вы решаете математическую задачу и ваше сознание переносится на ментальный план, то вы вдруг понимаете, что самолет уже приземлился, а время пролетело незаметно.

Время рождается на определенном этапе эволюции и на определенном этапе перестает существовать. Время перестает существовать в нашем земном понимании, когда сознанию становиться доступен план где все «здесь и сейчас». Ученые уже пытаются описывать физико-математическими моделями непроявленные (с точки зрения земного существования) планы бытия. Например, замечательно пространство $H$, которое предложил рассматривать Пенроуз, - $H=\mathbf{C P}^{3}$ (все $\mathbf{C P}^{3}$ шестимерно). Юрий Манин пишет по поводу этого пространства: «Сам „рай Пенроуза“" $H=\mathbf{C P}^{3}$ пространство, где помещаются все небеса, но ничего не осталось от земного пространства-времени, естественно назвать раем. ... Имеются глубокие физические основания считать, что мир, заполненный лишь излучением (или частицами, летящими с околосветовыми скоростями, почти вдоль световых конусов), должен лучше описываться в терминах геометрии $H$, чем уже привычного нам вещественного четырехмерья. K пространству-времени 
нас привязывает масса, она мешает нам лететь со скоростью света, когда время останавливается, а пространство теряет смыл. В мире света нет ни точек, ни времени; сотканные из света существа жили бы «нигде» и «никогда» (или «здесь» и «сейчас»), лишь поэзия и математика способны говорить о таких вещах содержательно [3]. Это вовсе не означает, что на плане, где отсутствует масса и мы имеем дело с тонкой энергией и существами «сотканными из света» отсутствует движение сознания этих существ и скорости мыслей, которые направляют эти сознания. Сознания сотканных из света тел определяются мыслями, они сосредоточены на том, на чем сосредоточена мысль, а скорость движения мысли - мгновенность. Мгновенность еще не осознанное свойство непроявленных планов бытия и обратная сторона Вечности. Время же физического мира там отсутствует.

\section{Запись 2}

Исследуя время, размышляя о нем, мы касаемся области философии. Древнегреческие философы размышляли о времени, пытались понять, время непрерывно или дискретно, как оно сочетается с вечностью и т. д. Большое влияние на понимание времени имело представление о времени Платона. Платон исходил из одного из своих основных тезисов о наличии двух миров, - вечного мира реальности (мира Идей) и мира его временных отражений (теней) в проявленном космосе. Эта идея стала краеугольным камнем платонизма и объективного идеализма в целом. Она была изложена Платоном в 360 году до нашей эры в седьмой главе его книги «Государство» («Миф о Пещере»). Согласно этой идеи, Вечность, по представлению Платона, принадлежит непроявленному плану Мирового Разума, о котором на данном этапе эволюции мы ничего знать не можем, можем только принять, что он существует. А время, по представлению философа, принадлежит проявленным планам, которые возникают из непроявленного и снова растворяются в нем. Циклы времени с древних времен рассматривались в различных религиозных философиях как Вечное Дыхание мира. Сегодня ряд ученых рассматривает гипотезу о периодическом рождении из плана непроявленного мира физического, его развития и последующего растворении опять в непроявленном. Так, рассматривается гипотеза, что эоны циклической Вселенной отделены друг от друга событием Большого Взрыва. Коллапс сверхмассивных «черных дыр» перед Большим Взрывам производит возмущения в виде гравитационных волн, которые, передают информацию от эона к эону и таким образом можно говорить об эволюции периодически возникающих космосов [4]. По последним данным ученых космос имеет малый объем вещества по сравнению с объемом «полевого пространства» или вакуума. А все малое говорит о его временности.

Содержательно говорить о таких вещах как непроявленные планы бытия с их атрибутами, такими как ритм, мгновенность, вечность, может не только поэзия и математика, но еще и музыка. Скрябин говорил о написании своей симфонии «Прометей»: «В «Прометее»у меня будут такие медленные темпы, которых никогда ни у кого не было, медленные как угодно - они должны длиться как вечность, - потому, что ведь это вечность должна пройти от момента томления до полной материализации... У меня 
будут и такие быстрые темпы, как никогда не были, в самом конце. В этот самый момент и будет созерцание гармонии, и наступит дематериализация, потому что это - одно и тоже [5]. Скрябин хотел в музыке отразить длительный путь «падения в материю», дифференциацию, разъединение для дальнейшего опыта прохождения пути поиска единства, а окончательный акт дематериализации он называл Мистерией. Мистерия как завершение «дня» эона, предпологала возвращение к Единству, лежащему в глубокой «ночи» эона. И так «сутки» за «сутками»....

\section{Запись 3}

Вечность по Платону есть прообраз, а время есть его образ, который тем не менее не может быть безотносительным к прообразу. Т. е. Вечность и время связаны как Идея и ее воплощение, как непроявленный Мировой Разум и космос. Мысля время соотнесенным с вечностью, Платон рассматривал его как категорию космическую, - оно возникает вместе с космосом, явлено в движении небесных тел и подчинено закону числа. Поскольку космос не вечен, то он может иметь так же и конец существования, а, следовательно, и конец времени данного цикла.

По закону аналогии, как уже было отмечено, человеческое время возникает на определенной стадии человеческой эволюции и перестает существовать на определенном этапе развития. Так же и для конкретного человека время не осознается с момента рождения, первые годы своей жизни человек ближе к ощущению какого-то безвременья, вечности и только с развитием сознания, годам к 4-5 в конкретную человеческую жизнь входит понятие время. - Мы имеем дело с целой иерархией циклов времени.

Возможно, что Боги говорят с людьми языком математики. Философская доктрина Платона о существовании мира Идей и мира их отражений (теней) уже нашла свое рассмотрение в математике [3,6]. Математическое моделирование процессов наблюдаемого мира в сочетании с идеями, их породившими, позволяет лучше понять как сами процессы, так и их идеи.

В нашем проявленном мире мы имеем дело с множеством разнообразных процессов, протекающих во времени: процессы рождения - гибели в живом веществе, создания - разрушения материалов различных конструкций, процессы роста кристаллов и разложения атомов...

Еще в XVII веке математик и философ Декарт высказал идею о существовании множества времен: для каждого процесса должно существовать индивидуальное время его протекания.

В XX веке в естествознание вошли понятия биологического и геологического времени, случайного имнимого времени и других времен. Время стало способом познания плотного мира и в каждом процессе и в каждом из видимых миров имеет свое особое относительное выражение.

Более глубокое понимания процессов, происходящих на Земле, по закону аналогий могут помочь глубже понять процессы происходящие в космосе и наоборот, ведь аналогичные процессы базируются на одних и тех же идеях. 
Запись 4

Великий Ньютон считается одним из основоположников современной науки. Исходя из своих философско-религиозных воззрений, он дал свое понимание времени. Так же как и Платон, Ньютон рассматривал два миpa, - мир божественный, совершенный и мир физический, наблюдаемый. Для божественного мира Ньютон ввел Абсолютное время,- для физического относительное. В божественном мире Ньютона время протекает с абсолютной математической точностью. Это означает, что два соседних промежутка времени совершенно равны друг другу. В физическом наблюдаемом мире, в отличие от мира божественного, все относительно недолговечно и время является атрибутом движения. Для этого мира Ньютон ввел относительное время.

В дальнейшем развитии науки Абсолютное время Ньютона стало употребляться как всеобщее и единственное время, принадлежащее миру в целом. Так продолжалось почти до XX века, когда это время обнаружило свое несовершенство. Физики вернули относительное время и Эйнштейн ввел четырехмерный пространственно-временной континиум, дополнив трехмерное пространство координатой времени.

Однако и это расширение рассмотрения времени не дало решения для многих процессов физического плана. Владимир Вернадский поднял вопрос о рассмотрения времени-дления в живой материи. Вернадский писал: «Время связано в нашем сознании с жизнью... Время, ранее существовавшее в сознании ученых как ни с чем не связанный параметр физических уравнений, есть явление природы, сопряженное с закономерными сроками существования вещества и живой материи» [2]. Вернадский считал, что время смены поколения организмов, жизни популяции, может быть принято за естественную единицу биологического времени при изучении биологических процессов. Ряд ученых сегодня высказывает мнение, что при математическом моделировании процессов в биологии нужно использовать именно биологическое время.

В своей Нобелевской лекции в 1977 году Илья Пригожин так же подчеркивал, что время не есть оторванный от реальных процессов параметр, он говорил: «Время приобретает свой истинный смысл, связанный с необратимостью, или даже с «историей» процесса, а не является просто геометрическим параметром, характеризующим движение».

Процессы протекающие в физическом мире живой и неживой природы зависят от многих случайных факторов. Поэтому возникла необходимость рассмотреть случайное время.

Размышляя о случайном времени, математик Юрий Кондратьев приводит простейший пример случайного времени: если мы возьмем несколько человек одинаковой физической подготовки, для которых характерна скорость пешего хода $4 \mathrm{kм} /$ час и которым нужно пройти 8 км, то реально, все они пройдут этот путь с разным временем, - на время прохождения пути может повлиять погода, встретившиеся по дороге события, количество остановок в пути для отдыха и т. д. - время прохождения пути будет случайным. Однако описание случайного времени потребует использования абсолютного времени Ньютона, что еще раз указывает на связь мира 
идеального и мира проявленного, физического. Времена различных процессов физического мира будут использовать для своего описания время Ньютона (или Платона), ибо возвращаясь к мифу Платона о «Пещере» физический мир есть «тень» мира идеального.

В зависимости от длительности процессов физического мира используются разные единицы времени, в основе которых лежат все те же годы или секунды, - числа по законам которых происходит движение космических тел. Для геологического времени используются декамериады (одна декамериада равна 100000 лет), для микропроцессов зептосекунды. В 2020 году физики из университета Гете в Германии (группа профессора Рейнхарда Дернера) измерили наименьший временной интервал в прямом измерении, - время требуемое фотону, чтобы пересечь молекулу водорода. Это время составило 247 зептосекунд или 2,47 × 10-19 секунды.

Время разных процессов, разные часы (солнечные, астрономические, атомные...), философские концепции о времени и научные эксперименты... Время остается загадкой и притягивает своими тайнами. В начале нашего века вышла в свет книга Крэйга Коллендера «Время в комиксах» (издание для досуга) и здесь следует отметить, что в этой «несерьезной» книге представлен вполне серьезный глоссарий основных терминов, имен и понятий о времени, он занимает 17 (!) страниц.

\section{Запись 5}

Общепринято считать, что человек обладает телом, душой и духом. Однако это утверждение часто воспринимается как религиозно-философская доктрина и наука на сегодняшний день не дает научного определения что такое душа или дух. Принято считать, что душа это нематериальная сущность человека, в которой выражена способность человека ощущать, мыслить, сознавать, чувствовать. Дух определяется как высшее проявление души человека, характеризующееся сильной волей и наделяющее человека способностью творить, быть сопричастным Творцу. В тоже время, мы видим, что научная трактовка человеческого сознания эквивалентна определению души. Ученые рассматривают сознание как научное понятие, включая в него способность воспринимать и творить информацию.

Исследованием сознания занимается не только психология («душа» по гречески «психе»), которая исследует влияние различных событий на наши чувства и мысли, влияние наших чувств и мыслей на сознания других людей, феномены гипноза и вспоминания событий далекого прошлого, и т. д. Исследованием сознания сегодня занимаются нейролингвистика и нейробиология. Нейробиология, в свою очередь, сотрудничает с информационной физикой, которая включает в себя разделы квантовой криптографии, квантовой телепортации, квантового компьютинга... Говоря о недоступном нам сегодня мире непроявленных планов бытия, мире всезнания и чувствопонимания, которые сегодня мы не можем исследовать никакими современными технологиями, мы можем подумать о единицах времени Планка. Одна единица времени Планка в 20 миллиардов раз меньше времени прохождения фотоном молекулы водорода и с нашей точки зрения может рассматриваться как Мгновенность. Мы можем рассмотреть едини- 
цы времени и во много раз меньшие единицы Планка и придти к осознанию беспредельности как Вечности так и Мгновенности, - атрибутов идеального мира где живут Идеи.

\section{Запись 6}

Отсутствие взаимопонимания между учеными и религиозными философами часто лежит в области терминологии. Как и термин «душа», понятие «аура» не популярно в научной среде, хотя вполне научно понятие «энергоинформационного поля» человека.

Еще в середине XX века физики Кирлиан сфотографировали электромагнитные излучения человека, а сегодня научно доказано, что нейроны мозга и нервные узлы человека могут излучать фотоны (свет) и, возможно, другие, еще не открытые частицы квантовых измерений. Энергоинформационное поле человека существует вне физического тела человека, но тесно связано с его мозгом и нервными узлами. Во время сна, когда связь энергоинформационного поля с мозгом ослабевает, «аура» получает некую свободу и возможность «путешествовать», может контактировать с планами более высоких измерений и получать от туда информацию. Эта информация, в свою очередь, будучи воспринята мозгом, кодируется ассоциациями нашего сознания и представляется нам в виде сновидения.

Здесь следует заметить, что время сна может не совпадать с временем приснившихся событий, - сон, (как правило) длящийся 120-180 секунд может переживаться как события многих часов. Так же следует отметить, что врачи анастезиологи часто отмечают явления, когда пациенты после наркоза рассказывают о событиях в которых не могли участвовать в реальной жизни.

\section{Запись 7}

В конце 60-тых годов прошлого века чешский ученый Иржи Земан написал книгу «Познание и информация» в которой рассмотрел вопрос о связи накопления информации и времени [7]. Он пришел к выводу, что расширение сознания за счет накопления информации влияет на время.

Умение анализировать информацию за счет развития ментальности, творить свою собственную информацию и посылать ее в пространство влияет на время. Время при движении от биосферы к ноосфере замедляется. Время стремиться к нулю при достижении всеведения и всезнания. Человек есть процесс, процесс развития сознания и движения в направление ноосферы. В данном процессе время выступает как атрибут сознания. Следовательно время есть атрибут эволюции в ее движении от материального к идеальному.

Гипотеза ученых о том, что существует связь между накоплением информации и временем нашла свои подтверждения в исследованиях ученых ряда университетов, исследования которых были опубликованы в журнале «Nature Communication» в октябре 2020. Ученые заявили об открытии феномена квантового замедления времени. Для изучения квантового замедления времени физики объединили принципы квантовой информатики с квантовой теорией гравитации. 
На наш физический материальный мир законы квантовой механики практически не влияют. Они не влияют на жизнь объектов крупнее атомов и заряженных частиц то той причине, что их работе на более крупных масштабах мешает замедление времени, порожденное гравитацией. И, как мы уже отмечали, в свою очередь, масса и заряд не позволяют частицам летать со скоростью света. Мир как бы состоит из минимум двух планов, - один состоит из атомов и молекул, это наш проявленный физический мир, где время положительно и следствия идут за соответствующими причинами, образуя пластичное будущее из-за свободной воли людей. На другом плане фотоны, нейтрино и другие еще не открытые частицы, которые движутся с околосветовыми, световыми и сверхсветовыми скоростями, являя с точки зрения Земли отрицательное время и разрывая причинно-следственные связи, ставя следствия впереди причин, что не находит объяснения в классической физической науке, но может быть объяснено в квантовой физике. Возможно проблему причинно-следственных связей в квантовых измерениях можно будет решить с использованием теоремы Роберта Героха (Robert Geroch. Geroch's splitting theorem).

В фильме Андрея Тарковского «Андрей Рублев», явившийся Рублеву дух его умершего учителя Феофана Грека говорит: «Здесь все не так, как у вас на Земле...».

Наука уже вплотную подошла к изучению границы между нашим проявленным физическим миром и миром, где живут «существа из света».

\section{Запись 8}

Квантовая физика приоткрывает завесу жизни на планах, где живут человеческие сознания или «существа из света» и позволяет получить некоторые представления о тайнах пространства-времени на этих планах. Одна из тайн, - квантовая суперпозиция. Суперпозиция есть понятие о том, что крошечные объекты могут существовать в нескольких местах или состояниях одновременно. Ученые предположили наличие у квантовой частицы волновых свойств и эксперимент подтвердил, что фотон реально может пройти одновременно через две щели, расположенные в разных местах пространства. В этом случае можно представить, что фотон находится в состоянии пространственной протяженности. И это похоже на то, что религиозные философы называют «делением духа».

В 1961 году в Лондоне вышла знаменитая работа Юджина Вигнера о сознании в квантовых измерениях, - «Remarks on the mind-body question». Вигнер начал эту статью очень смелым для своего времени (и для нашего времени тоже) замечанием: «Всего несколько лет назад «существование» ума или души страстно отрицалось большинством ученых-физиков. Блестящие успехи механической и, в более общем плане макроскопической физики и химии затмило очевидный факт, что мысли, желания и эмоции не состоят из материи, ...».

Один из выводов, которые делает в своей работе Вигнер, - это то, что квантовое описание объектов подвергается влиянию впечатлений от мыслительных и чувственных процессов, входящих в сознание. Вигнер делает так же вывод, что человеческое сознание может влиять на окружа- 
ющий мир и можно продолжить это утверждение, сказав, что сознание может влиять на время.

В процессе познания наукой тех составляющих человека, которые принято называть душа и дух, открытия законов планов их обитания, придет понимание еще многих особенностей времени и оно перестанет быть тайной. А пока мы имеем самые разные теории времени, начиная от теорий отрицания существования времени, до теорий циклов времени, сторонников и противников теории «стрелы времени»и т. д.

\section{Запись 9}

Сегодня, некоторые гении человечества, достигая в духе высоких планов бытия, приносят нам оттуда информацию, позволяющую приблизиться к тайне времени.

Выдающийся композитор Софья Губайдулина пишет: «Хочу в своей музыке осуществить настоящее длящееся время, которого в жизни нет. В жизни-то нет настоящего длящегося времени - мы не имеем вообще настоящего времени в жизни, мы все время переходим из прошлого в будущее, ... по существу, только в искусстве можно достичь, когда настоящее длится, и оно длится с помощью музыкальной формы». [8]

Как можно представить настоящее длящееся время? - Все космические тела излучают лучи, то есть отражают себя в пространстве. И Землю достигают лучи давно погасших и умерших планет. Луч несет в себе историю (информацию) исчезнувшего мира как бы вытянутого в пространстве в течении миллионов или миллиардов лет полета этого луча в космосе. Но этот протяженный во времени в мировом пространстве луч существует в нем ныне, в настоящем, как одно целое. В Космосе существует великое вечное ныне, запечатленное в лучах от космических тел. Если бы мы могли нашими мыслями и сознанием касаться срезов этих лучей, мы могли бы получать информацию о происходившем в тот момент на данном космическом объекте. Мы можем иметь отражение этого явления в нашей земной жизни как, например, фильм или альбом с фотографиями человека, который уже умер, но фильм или этот альбом находятся в настоящем и мы можем в любой момент коснуться нашим сознанием моментов этого прошлого.

Наше земное вчера, сегодня, завтра есть отражение космического прошлого, существующего в длящемся настоящем и будущего, которое будучи запланировано высшим разумом и результатом причинно-следсвенных связей становится уже прошедшим. И только закон свободной воли вносит свои корректировки в будущее, делая возможным эволюционное развитие. И в этом длящемся настоящем нет нашего земного пространства - времени а есть «здесь и сейчас», которое наука еще должна изучить.

Сегодня мы можем сформулировать два аспекта тайны времени: тайна прошедшего и будущего в длящемся настоящем и тайна пространства времени как квантовой суперпозиции, возможности нахождения сознания одновременно в разных точках пространства. Обе эти тайны связаны со способностью нашего сознания существовать на разных планах бытия, в пространствах более высоких измерений. 
Наше сознание, имея свойство излучать, придает своим частицам волновые свойства и дает возможность находится им в радиусе своего луча. Чем выше напряжение сознания, тем больше пространство в котором оно может пребывать. (Это как луч от карманного фонарика или от мощного прожектора.) K тайнам пространства-времени, а, следовательно, и к тайнам жизни человека на разных планах бытия, уже вплотную подошла наука. И можно только мечтать как преобразиться жизнь человечества, когда эти тайны перестанут быть тайнами.

Выдающийся математик и кибернетик Виктор Глушков, создатель первого в СССР персонального компьютера, будучи тяжело болен, в последнем разговоре с женой вспомнил как в молодости дарил ей далекие созвездия и желая утешить сказал: «Не расстраивайся! Ведь через подаренные мной созвездия когда-нибудь будет проходить свет нашей Земли, и на каждом мы будем появляться снова молодыми. Так и будем в вечности всегда вместе!» [9].

\section{Reference}

[1] Wigner J.P. 1961. Remarks on the mind-body question. The scientist speculates / Ed. L. G. Good. London : Heinemann.

[2] Aksenov G.P. 2010. V.I. Vernadskij o prirode vremeni i prostranstva. Moskva., Krasandr.

[3] Manin Y. I. 2007. Mathematical as Metaphor Providence, AMS.

[4] Penrose R. 2010. Cycles of Time, Bodley Head (UK).

[5] Sabaneev L. L. 2000. Vospominanija o Skrjabine. Moskva (reprint 1924).

[6] Kondratiev Y. G. 2020. Applied philosophy in mathematics. Interdisciplinary studies of complex systems Ed. by D. Finkelshtein, Yu. Kondratiev. Kherson : Helvetica.

[7] Zeman I. 1966. Posnanie i informazija. Moskva, Progress.

[8] Smirnov D. Intervju s Cofiej Gubajdulinoj, 09.06.2001.

[9] Malinovsky B. 2007. Store eternally, Kyiv : Gorobez. 